\title{
Perilunate Dislocation: Case Report
}

\author{
Perilunat Çıkı: Olgu Sunumu
}

\author{
Ahmet İmerci', Mahmut Tuzlu², Hüseyin Tamer Ursavaş², Muhammet Bozoğlan³, Umut Canbek ${ }^{4}$ \\ 'Department of Orthopaedics and Traumatology, Erzurum Palandöken State Hospital, Erzurum, Turkey \\ ${ }^{2}$ Department of Orthopaedics and Traumatology, Izmir Tepecik Training and Research Hospital, Izmir, Turkey \\ ${ }^{3}$ Department of Orthopaedics and Traumatology, Mardin Derik State Hospital, Mardin, Turkey \\ ${ }^{4}$ Department of Orthopaedics and Traumatology, İmir Karşıyaka State Hospital, İzmir, Turkey
}

\section{ABSTRACT}

Occult perilunate dislocations can accompany wrist injuries. Without treatment, these dislocations have a high possibility of long-term functional impairment and chronic pain. After the aforementioned trauma, a differential diagnosis of perilunate dislocation must be kept in mind by emergency physicians. A careful physical and radiological examination is a crucial element in this setting as one must exclude perilunate dislocation. Carpal fracture/dislocation should be considered following trauma to this region. This paper discusses a case of perilunate dislocation after a wrist injury and presents a review of the literature with tips for diagnosis.

Keywords: Perilunate dislocation, emergency medicine, diagnosis

Received: 30.05.2011 Accepted: 22.11.2011

Available Online Date: 20.05.2013

\section{ÖZET}

El bileği travmalarına, lunatum çevresinde gizli çıkıklar eşlik edebilir. Bu çıkıklar tedavi edilmedikleri zaman; uzun dönemde fonksiyonel sakatlık ve kronik ağrı görülme olasılığı yüksektir. Perilunat çıkık, bu tarz travmalar sonrası acil hekimleri tarafından ayırıcı tanıda mutlaka akılda tutulmalıdır. Dikkatli bir fizik muayene ve radyolojik inceleme bu konuda en önemli unsurlardır. Mutlaka perilunat çıkık dışlanmalıdır. Bu bölge travmalarında karpal kemiklerin çıkık/kırık olma olasıığıda akılda bulundurulmalıdır. Bu yazıda el bileği travması sonrası geliş̧en perilunat çıkık olgusu literatür eşliğinde tanı ipuçları ile sunulmuştur.

Anahtar Kelimeler: Perilunat çıkık, acil servis, tanı

Geliş Tarihi: 30.05.2011 Kabul Tarihi: 22.11.2011

Çevrimiçi Yayın Tarihi: 20.05.2013

\section{Giriş}

Perilunat çıkık, el bileğinde lunatumun komşu karpal kemiklerle ve distal radiusla ilişkili olan, kapsül ve bağ dokularının ilerleyici hasarı ile karakterize çıkık tipidir (1). Perilunat çıkıklar veya kırıklı çıkıklar oldukça nadir görülür. Genellikle yüksek enerjili travmalarda açık el üzerine düşme sonrası elin hiperekstensiyon ve ulnar deviasyona zorlanmasıyla oluşmaktadır. Perilunat çıkıkların direkt radyografik bulguları tanımlanmıştır. Fakat başlangıç filmlerinin çoğu zaman yanlış yorumlanmasından dolayı tanı koymada ve erken müdahelede çoğu zaman gecikmeler yaşanır. Karpal kemik yapılarının karmaşıklığı ve radyolojik incelemelerde elbileğinin pozisyonunun belirleyiciliği nedeniyle acil serviste direkt grafileri yorumlaması her zaman çok kolay olmamaktadır. Bu sebeple çoğu patolojik bulgu gözden kaçmaktadır (1-5). Bu yazıda bir olgu eşliğinde, perilunat çıkıklar ve bu çıkıkların tanı ipuçları literatür eşliğinde gözden geçirilmesi amaçlanmıştır.

\section{Olgu Sunumu}

Altmış bir yaşında marangozluk yapan erkek hasta, iş yerinde 2 metre yüksekten açık el üzerine düşme sonrası sol el bileğinde ağrı, şişlik ve hareket kısıtlığı şikayetleriyle acil servise başvurdu. Yapılan fizik muayenesinde sol el bileğinde şişlik ve palpasyon ile ağrısı mevcuttu. Belirgin deformitesi yoktu. Periferik nabızları açıktı ve nörolojik muayenesi normaldi. Sol el bileğinin direkt grafileri çekildiğinde, posterior anterior grafide, karpal kemikler arasındaki ilişkiyi işaret eden proksimal karpal sıranın proksimal ve distal konturlarında devamlılık kaybı olduğu, lunatumun normal dörtgen görünümünü kaybedip üçgen şeklini aldığı ve skafoidle lunat kemikler arasındaki eklem mesafesinin artmış olduğu görüldü (Resim 1a). Lateral grafide lunatumun distal çukurluğunun kapitatumun başı ile eklem yapmadığı görüldü (Resim 2a). 


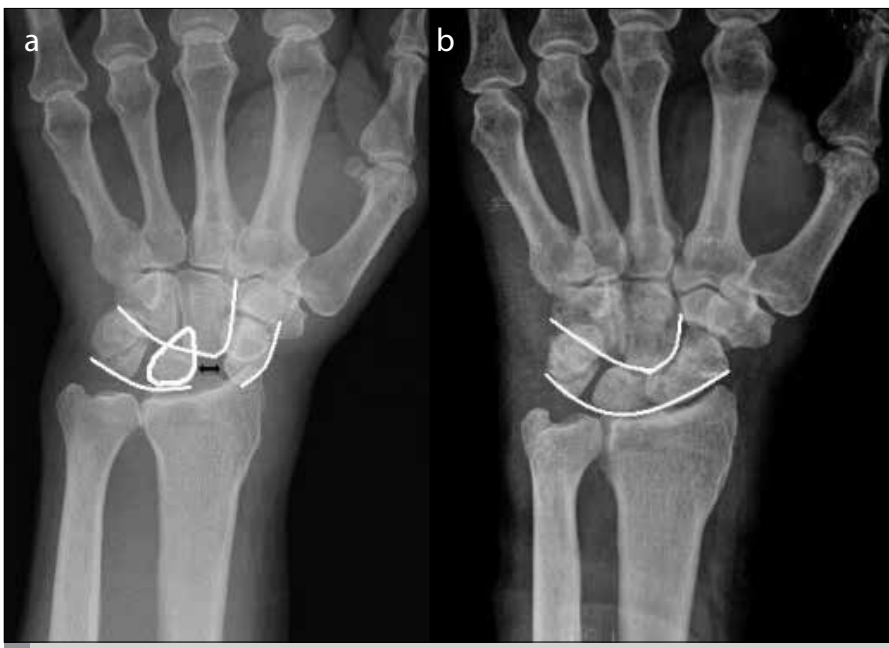

Resim 1a. Tedavi öncesi direkt posterior anterior grafide sol el bileğinde skafolunat ayrışma, karpal kemikler arasındaki proksimal ve distal konturların devamlılığının bozulması, b. Tedavi sonrası normal posterior anterior grafi

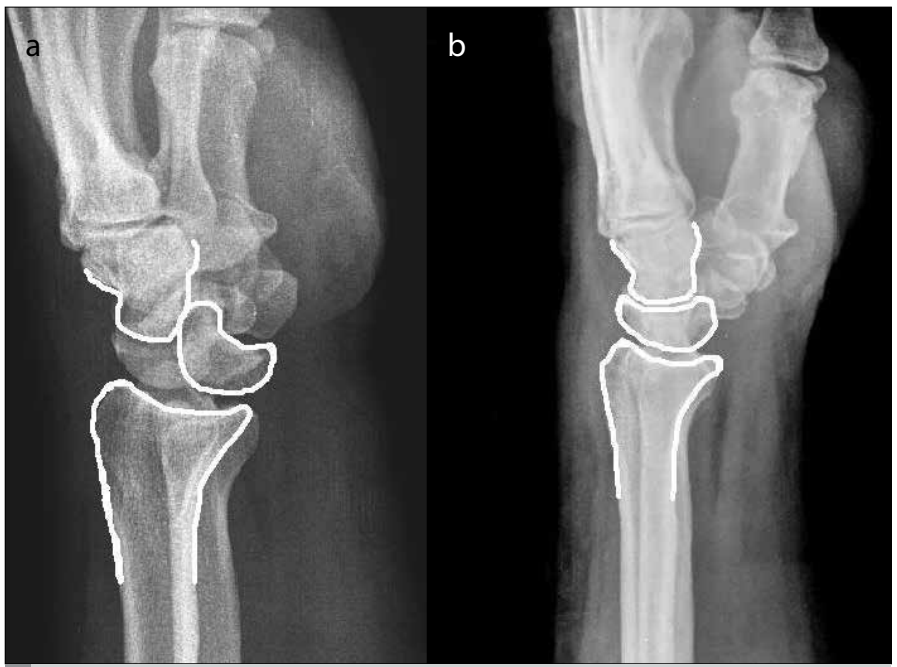

Resim 2a. Tedavi öncesi direkt lateral grafide dorsal lunatokapitat eklem çıkığı, b. Tedavi sonrası normal lateral elbileği grafisi, lunatum ile kapitatum arasında ve lunatum ile distal radius arasındaki normal ilişki görülmekte

Hasta ortopedi hekimlerince konsülte edildi. Olgumuza dorsal perilunat çıkık (evre 4) tanısı konuldu. Acil olarak ameliyathane şartlarında rejyonel anestezi altında kapalı redüksiyonu ve takiben cerrahi tedavi uygulandı. Hasta komplikasyonsuz olarak iyileşti (Resim 1b, 2b).

\section{Tartışma}

Elbileği çıkıklarının en sık görüleni olan perilunat çıkık; tüm elbileği yaralanmalarının ise \%2'sini oluşturur $(1,4)$. Vakaların \%97'sinde çıkık dorsaledir. Bu çıkıkların \%25 kadarı başlangıçta atlanmaktadır. Tanıda oluşan bu gecikme yaşam kalitesini ve tedavi sonuçlarını önemli derecede olumsuz etkilenmektedir $(1,6,7)$. Erken tanı tedavinin başarısı açısından kritik öneme sahiptir. Geç tanınan çıkıklarda devam eden median sinir kompresyonuna bağlı karpal tünel sendromu gelişebilmektedir (5). Yine geç tanınan vakalarda sık olarak elbileğinde kronik ağrı ve sakatlık gelişmektedir.
Tanı; anamnez, fizik ve radyolojik muayeneye ile konur. Fizik muayene sıklıkla spesifik değildir. Elbileğinde ciddi bir ağrı, şişlik ve hareket kısıtlığı mevcuttur. Hikaye ve fizik muayene sonrası radyografik değerlendirmeye geçilir (6). Tanı dikkatli bir röntgen muayenesine dayanır. Temel olarak standart posterior anterior ve lateral grafiler çekilmelidir. Perilunat çıkığın grafi bulguları şunlardır:

\section{Direkt posterior anterior grafide;}

a. Terry Thomas işareti: Skafolunat aralığın 2-3 mm den fazla olması, skafolunat ayrışma.

b. Gilula arkları: Karpal kemikler arasındaki proksimal ve distal konturların devamlılı̆ının kaybı (5).

c. Lunatumun normal dörtgen şeklini kaybedip üçgen şeklini alması.

\section{Direkt lateral grafide;}

a. Lunatumun distal çukurluğunun kapitatumun başı ile eklem yapmaması.

b. Radius, lunatum ve kapitatumun normal sıra halinde diziliminde bozukluk olması $(1,2,5,6)$

lunat veya perilunat çıkık konusunda uyarıcı olmalıdır. Bizim olgumuzda da tüm bu bulgular izlenmektedir (Resim 1a, 2a).

Genellikle yüksek enerjili travmalar ile oluşan ve açık el üzerine düşmeye bağlı el bileğinin zorlu hiperekstensiyonuyla gelişen lunatumun anatomik ilişkilerinde ve ligament bağlantılarındaki ilerleyici bozukluklar, Mayfield ve arkadaşları tarafından dört evrede sınıflanmıştır $(1,2,6)$

1. Skafoid kırığı veya skafolunat ayrışma veya her ikisi

2. Lunatokapitat çıkık

3. Lunatotrikuetral ayrılma

4. Perilunat çıkık

Bu çıkıklar acil serviste mutlaka ortopedi hekimlerince konsülte edilmelidir. Akut çıkıklar veya kırıkı çıkıklar bölgesel veya genel anestezi altında acil olarak redükte edilmelidir (1, 3). Çıkığın dengeli hale gelmesi sağlanmalıdır. Bizim olgumuza çıkığın yönünün dorsale olması ve lunatumun skafoid, kapitatum ve triquetrumla olan eklemlerinin bozulması nedeniyle dorsal perilunat çıkık (evre 4) tanısı konuldu. Ortopedi konsültasyonu ile değerlendirilmesi yapılan hastaya cerrahi müdahale düşünüldü. Hastamız ortopedi servisine yatırılarak cerrahi tedavi uygulandı.

\section{Sonuç}

Perilunat çıkıklar veya kırıkı-çıkıklar erken tanınmadığı zaman sıklıkla daha az başarılı olan gecikmiş tedavilere yol açarak hastaların yaşam kalitesini oldukça olumsuz etkileyen bir yaralanma türüdür. Her ne kadar literatürde daha önce sıkça tanımlanmış bir olgu olsa da, çok sık rastlanmaması ve grafilerin dikkatsiz ve alelacele yorumlanırsa kolaylıkla gözden kaçabilmesi nedeniyle acil hekimlerinin el bileği travması ile başvuran hastaların ayırıcı tanısında radius distal kırığı ve skafoid kırığı yanında mutlaka perilunat çıkık veya kırıklı çıkık olabileceğini de düşünmelidir.

\section{Conflict of Interest}

No conflict of interest was declared by the authors. 
Peer-review: Externally peer-reviewed.

\section{Author Contributions}

Concept - A.I., M.T.; Design - A.I., U.C.; Supervision - H.T.U., M.B.; Funding - A.I., M.T.; Materials - A.I.; Data Collection and/or Processing - A.I., M.T., H.T.U., M.B., U.C.; Analysis and/or Interpretation - A.I.; Literature Review - M.T., H.T.U., M.B.; Writer - A.I.; Critical Review - M.B., U.C.

\section{Çıkar Çatışması}

Yazarlar herhangi bir çıkar çatışması bildirmemişlerdir.

Hakem değerlendirmesi: Dış bağımsız.

\section{Yazar Katkıları}

Fikir - A.I., M.T.; Tasarım - A.I., U.C.; Denetleme - H.T.U., M.B.; Kaynaklar A.I., M.T.; Malzemeler - A.I.; Veri toplanması ve/veya işlemesi - A.I., M.T., H.T.U., M.B., U.C.; Analiz ve/veya yorum - A.I.; Literatür taraması - M.T., H.T.U., M.B.; Yazıyı yazan - A.I.; Eleştirel İnceleme - M.B., U.C.

\section{Kaynaklar}

1. Rockwood CA, Jr, Green DP, Bucholz RW. Fractures and dislocations of the wrist, in Rockwood CA, Jr, Green DP (eds): Fractures in Adults, Vol 1. New York, Lippincott Williams \& Wilkins Publishers, 2011.pp.857-908.

2. Perron AD, Brady WJ, Keats TE, Hersh RE. Orthopedic pitfalls in the ED: lunate and perilunate injuries. Am J Emerg Med 2001; 19: 157-62. [CrossRef]

3. Chin HW, Uehara DT. Wrist injuries, in Tintinalli JE, Kelen GD, Stapczynski JS (eds): Emergency Medicine, New York, McGraw- Hill, 2000.pp.1772-83.

4. Ada S, Özerkan F, Bora A, Ademoğlu Y, Kaplan İ. Perilunate kırıklı-çıkıkların cerrahi tedavi sonuçları. Acta Orthop Traumatol Turc 1995; 29: 263-7.

5. Sochart DH, Birdsall PD, Paul AS. Perilunate fracture-dislocation: a continually missed injury. J Accid Emerg Med 1996; 13: 213-6. [CrossRef]

6. Kardashian G, Christoforou DC, Lee SK. Perilunate Dislocations. Bull NYU Hosp Jt Dis 2011; 69: 87-96.

7. Herzberg G, Comtet JJ, Linschied RL, Amadio PC, Cooney WP, Stadler J. Perilunate dislocations and fracture dislocations; a multicenter study. J Hand Surg 1993; 18-A: 768-79. 